This article is licensed under the Creative Commons Attribution-NonCommercial 4.0 International License (CC BY-NC) (http://www.karger.com/Services/OpenAccessLicense). Usage and distribution for commercial purposes requires written permission.

\title{
Long-Term Efficacy of S-1 Chemotherapy plus Administration of Octreotide for a Patient with Metastatic Neuroendocrine Tumor (Gastrinoma)
}

\author{
Sakura Hiraide $^{a}$ Sadahide Ono $^{b}$ Satoshi Kato ${ }^{a}$ \\ ${ }^{a}$ Department of Clinical Oncology, Iwate Prefectural Central Hospital, Morioka, Japan; \\ ${ }^{b}$ Department of Pathology, Iwate Prefectural Central Hospital, Morioka, Japan
}

\section{Keywords}

Gastrinoma Octreotide $\cdot$ S-1 $\cdot$ Chemotherapy

\begin{abstract}
Metastatic neuroendocrine tumors (gastrinomas) have a poor prognosis. Octreotide can reduce gastrin levels and alleviate hormonal symptoms, and possibly slow tumor growth as well. No drugs were available except streptozocin for the treatment of metastatic pancreatic neuroendocrine tumor (PNET) in 2008. We report a case of PNET in a 53-year-old woman with multiple liver tumors treated with S-1 plus octreotide. After 6 months from the initiation of the treatment, the pancreatic tumor and liver metastases regressed, and the patient achieved partial response without the development of any serious adverse event. For more than 8 years, the patient has remained asymptomatic without disease progression and is continuing treatment with octreotide and S-1. A marked suppression of gastrin levels has also been achieved. Combination therapy with octreotide and S-1 has been effective and well tolerated in patients with metastatic gastrinoma.

(C) 2017 The Author(s)

Published by S. Karger AG, Basel
\end{abstract}




\section{Case Reports in Oncology}

\section{Introduction}

Gastrinoma is a neuroendocrine tumor (NET) that secretes excess amounts of gastrin. It causes peptic ulcer in the duodenum, stomach, and small intestine. The 5-year survival rate of patients with metastatic gastrinoma is reported to be about 20-40\% [1].

Somatostatin analogues (SSAs), octreotide and lanreotide, are effective for the management of functional NETs. While SSAs are used to control the symptoms due to release of bioactive amines, such as gastrin, it has been suggested that they have the ability to suppress the growth of advanced NETs.

For the treatment of unresectable NETs, the National Comprehensive Cancer Network (NCCN) guidelines recommend cytotoxic chemotherapy in combination with other treatment methods. Although S-1, an oral fluorinated pyrimidine, is not referred to in the NCCN guidelines, it has an indication for the treatment of a wide variety of gastrointestinal tract neoplasms containing pancreatic cancer in Japan.

Here, we present a patient with metastatic gastrinoma who has shown a good response to $\mathrm{S}-1$ and octreotide for more than 8 years.

\section{Case Presentation}

In 2008, a 53-year-old woman presented with elevated levels of liver enzymes. Abdominal sonography revealed multiple liver tumors without symptoms. She had a history of duodenal ulcer for 2 years and had received proton pump inhibitor treatment. No particular family history was noted. A computed tomography (CT) scan showed a slightly enhanced pancreatic tail tumor, measuring $53 \mathrm{~mm}$ in diameter (Fig. 1a). There were prominent multiple metastatic tumors in the liver, which had a maximum diameter of $32 \mathrm{~mm}$ (Fig. 1a). No abnormal findings were noted in the upper and lower gastrointestinal endoscopic examinations. The clinical staging was T3N0M1 stage IV tumor according to the TNM classification. The Eastern Cooperative Oncology Group (ECOG) performance status was 0. Hormonal evaluation revealed increased levels of gastrin to $450,000 \mathrm{pg} / \mathrm{mL}$ (normal range: 30-150 $\mathrm{pg} / \mathrm{mL}$ ), but other pancreatic hormones were not elevated.

Needle biopsy of the liver tumor showed malignant cells proliferating in a trabecular pattern (Fig. 2a). Immunohistochemical staining showed that the tumor cells were positive for synaptophysin (Fig. 2b), and the Ki-67 index was 29.1\% (Fig. 2c). Structural atypia was not so remarkable. We made a pathological diagnosis of a well-differentiated endocrine carcinoma according to the 2004 World Health Organization (WHO) classification, which corresponded to intermediate-grade (grade 2) NET based on the 2010 WHO classification. These findings were consistent with grade 2 pancreatic NET (gastrinoma). There were no family history or other accompanying tumors related to multiple endocrine neoplasia type 1 (MEN-1).

She received subcutaneous injections of octreotide at a dose of $50 \mu \mathrm{g}$ every $12 \mathrm{~h} ; 4$ days later, the dose of octreotide was increased to $100 \mu \mathrm{g}$ every $12 \mathrm{~h}$ without side effects. Changes in the serum gastrin levels are shown in Figure 3, indicating a significant decrease after the start of octreotide treatment. For convenience, her treatment was changed to $20 \mathrm{mg}$ of longacting intramuscular octreotide once a month following $200 \mu \mathrm{g}$ daily injections. In conjunc- 


\section{Case Reports in Oncology}

tion with octreotide treatment, oral S-1 $\left(40 \mathrm{mg} / \mathrm{m}^{2}\right.$ body surface area), was administered twice daily on days 1-28. Administration was repeated every 6 weeks. Regression of the metastatic tumors of liver on enhanced abdominal CT scans is shown in Figure 1. After 6 months (4 cycles of chemotherapy with S-1), a CT scan revealed that the diameter of the pancreatic tumor had decreased to $28 \mathrm{~mm}$ (Fig. 1b). According to the response evaluation criteria in solid tumors (RECIST) version 1.1, we considered that this patient had achieved a partial response. Four years later, we recommended her to have a surgery; however, she did not agree to undergo the surgery and chose to continue with chemotherapy. The patient has showed good response to the treatment for more than 8 years, and she continues to receive S-1 and octreotide therapy. Her gastrin level has decreased to $850 \mathrm{pg} / \mathrm{mL}$, and she remains asymptomatic with no disease progression (Fig. 3).

\section{Discussion}

The 2003 WHO classification subdivides pancreatic gastrinomas into three general categories. About $10-30 \%$ of gastrinomas are well-differentiated endocrine tumors, $50-80 \%$ of gastrinomas are well-differentiated endocrine carcinomas, and only 1-3\% of gastrinomas are poorly differentiated endocrine carcinomas [1]. The 2004 WHO classification used a hybrid of grading (the inherent biologic aggressiveness of the tumor as assessed by histologic features) and staging. According to the 2010 WHO classification, neuroendocrine neoplasms are classified by their proliferative rates. Some reports suggest that NET grade 3 and neuroendocrine carcinomas are heterogeneous, and propose the introduction of a new category of neuroendocrine neoplasms characterized by well-differentiated tumor morphology and MIB-1 index $>20 \%$, named grade 3 well-differentiated NETs [2]. In our case, structural atypia was not remarkable and the MIB-1 index was $29.1 \%$. Our case, therefore, corresponds to grade 3 well-differentiated NETs, and these patients survive longer than those with MIB-1 index $>55 \%$ [2].

According to the NCCN guidelines for NETs, octreotide is recommended for patients with metastatic gastrinoma. Furthermore, the management of gastrinoma with unresectable liver metastases includes hepatic regional therapy, cytoreductive surgery, everolimus, sunitinib, and cytotoxic chemotherapy [1].

The antitumor effects of octreotide LAR (long-acting release) were reported in the PROMID study in patients with metastatic neuroendocrine midgut tumors. A significant improvement in median time-to-progression (TTP) from 6 months in the placebo group to 14.3 months in the octreotide LAR group was observed [3]. The CLARINET trial showed that treatment with lanreotide, a long-acting SSA, significantly improved progression-free survival in patients with NETs of both gastrointestinal and pancreatic origins. For this study, all subgroups demonstrated a significant or strong trend toward improved progression-free survival with lanreotide, including midgut and pancreas primaries, grade 1 and 2 , and hepatic tumor volume $\leq 25 \%$ or $>25 \%$ [3].

Shojamanesh et al. [4] reported that the response rate to octreotide in patients with malignant gastrinoma (rate of tumor regression of more than 25\% decrease in tumor size) or tumor stabilization was 53\%, and the mean duration of response was 25.0 months. In that study, slow-growing NETs (slow tumor growth was defined as a 1-50\% increase in tumor 


\section{Case Reports in Oncology}

volume per month) responded better to octreotide treatment, and there was a tendency toward longer survival. On the other hand, octreotide monotherapy seems insufficient for rapid-growing NETs (rapid tumor growth was defined as $>50 \%$ increase in tumor volume per month). There was a trend of responsiveness to chemotherapy in tumors with high Ki67 index. As a criterion for selecting patients for cytotoxic treatment, Vilar et al. [5] proposed that the Ki-67 index should be $>10 \%$.

Our case had several characteristics that were considered as unfavorable prognosis, including liver metastases, Ki-67 index $>2$, exclusion of MEN-1, markedly increased fasting gastrin levels, presence of a large primary tumor $(>3 \mathrm{~cm})$, a pancreatic primary gastrinoma, and female gender [1]. We considered cytotoxic agents were preferable for the treatment of our patient because of the high Ki-67 index and unfavorable prognosis risk factors.

Previously, a combination of streptozocin and fluorouracil was shown to be effective and safe for the treatment of NETs by several clinical trials [1]. However, when we started the treatment in 2008, streptozocin, a traditionally used cytotoxic drug, was not used in Japan. On the other hand, S-1, an oral fluorinated pyrimidine was indicated for the treatment of pancreatic cancers in Japan. Hence, we decided to administer chemotherapy with S-1 and octreotide. To the best of our knowledge, several patients with pancreatic NETs who were treated with S-1 have been reported in the Japanese and English literature (Table 1) [6-15]. S-1 was used as a single agent, as well as in combination therapy. S-1 consists of a combination of drugs such as octreotide, gemcitabine, and streptozocin. The anti-growth effect of S-1 containing chemotherapy varies from partial response to progressive disease by case reports [6-15].

In our case, good clinical response and marked tumor reduction was achieved by combination therapy with octreotide and $S-1$, thereby enabling progression-free survival for over 8 years to be achieved. Additionally, this case suggests that combination therapy with octreotide and S-1 can be efficacious and well tolerated in patients with metastatic gastrinoma.

\section{Statement of Ethics}

The authors have no ethical conflicts to disclose.

\section{Disclosure Statement}

The authors declare that there is no conflict of interest regarding the publication of this paper. 


\section{References}

1 Jensen RT, Niederle B, Mitry E, et al: Gastrinoma (duodenal and pancreatic): ENETS Guidelines. Neuroendocrinology 2006;84:173-182.

2 Caplin ME, Pavel M, Ruszniewski P, et al: Lanreotide in metastatic enteropancreatic neuroendocrine tumors. N Engl J Med 2014;371:1556-1557.

-3 Milione M, Maisonneuve P, Spada F, et al: The clinicopathologic heterogeneity of grade 3 gastroenteropancreatic neuroendocrine neoplasms: morphological differentiation and proliferation identify different prognostic categories. Neuroendocrinology 2017;104:85-93. Shojamanesh H, Gibril F, Louie A, et al: Prospective study of the antitumor efficacy of long-term octreotide treatment in patients with progressive metastatic gastrinoma. Cancer 2002;94:331.

5 Vilar E, Salazar R, Pérez-García J, et al: Chemotherapy and role of the proliferation marker Ki-67 in digestive neuroendocrine tumors. Endocr Relat Cancer 2007;14:221-232.

6 Takeuchi H, Fujita H, Kondo A, et al: A case of recurrent islet cell carcinoma of the pancreas 17 years after the initial surgery. J Jpn Surg Assoc 2008;69:1514-1518.

7 Masuda T, Kuwahara A: A long-term survival case of unresectable malignant pancreatic endocrine tumor successfully treated with systemic chemotherapy. Gan To Kagaku Ryoho 2008;35:833-835. Nishii T, Amano R, Nakao S, et al: A case of liver metastasis of mixed acinar-endocrine carcinoma treated with various loco-regional cancer therapies. Gan To Kagaku Ryoho 2008;35:2126-2128.

9 Nishimura K, Shima Y, Nakamura T, et al: A resected case of hepatic metastasis of gastrinoma with tumor thrombus in the inferior vena cava. Journal of Biliary Tract and Pancreas 2009;30:103-107.

10 Sato I, Ueda N, Kinoshita E, et al: Curatively resected case of non-functioning pancreatic neuroendocrine carcinoma with multiple liver metastases after downstaging with S-1 monotherapy. Gan To Kagaku Ryoho 2010;37:1341-1344.

11 Yamamoto M, Miyagawa K, Hiura M, et al: Poorly differentiated neuroendocrine carcinoma of the pancreas responsive to combination therapy with gemcitabine and S-1. Intern Med 2012;51:727-732. Yoshida Y, Sugawara N, Minami T, et al: A case of pancreatic neuroendocrine tumor with excessivelyadvanced liver metastasis treated with S-1/GEM combination chemotherapy plus the long-acting somatostatin analogue octreotide. Nihon Shokakibyo Gakkai Zasshi 2013;110:660-668.

13 Kanemasa Y, Kamisawa T, Tabata T, et al: Mixed acinar-endocrine carcinoma of the pancreas treated with S-1. Clin J Gastroenterol 2013;6:459-464.

14 Yoshizawa N, Hijioka S, Mizuno N, et al: A patient with a pancreatic neuroendocrine tumor who developed everolimus-induced interstitial pneumonia: a case report. Nihon Shokakibyo Gakkai Zasshi 2014;111:1820-1828.

15 Yoshioka M, Shibata S, Uchinami H, et al: The transformation of a nonfunctioning islet cell tumor of the pancreas into a proinsulinoma under conditions of lung metastasis. Intern Med 2015;54:785-790. 


\section{Case Reports in Oncology}
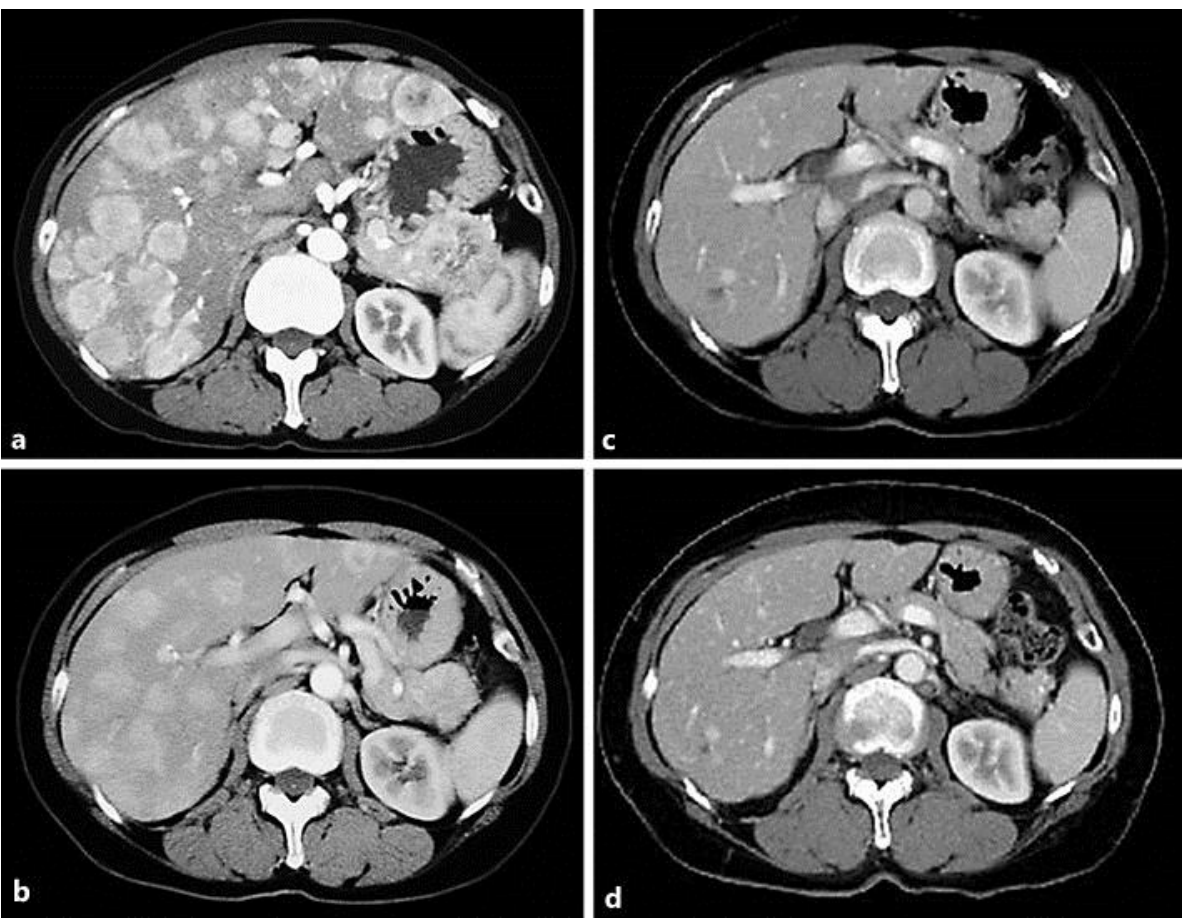

Fig. 1. Enhanced computed tomography (CT) images before the treatment with S-1 and octreotide showed the pancreatic tumor and multiple liver metastases (a). CT images 6 months after the initiation of treatment (b), and images taken at 4 years (c) and 7 years (d) after the initiation of chemotherapy, revealing that the tumor had regressed.
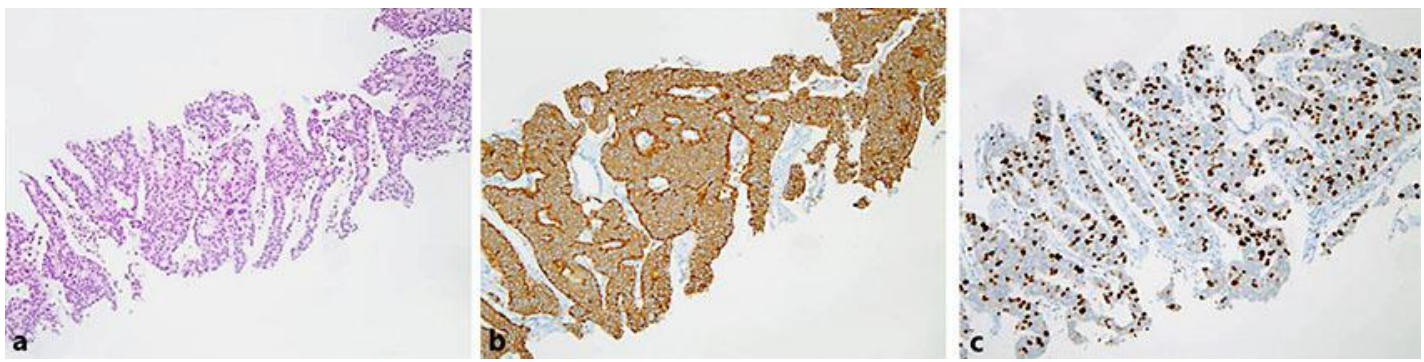

Fig. 2. a Histological examination with hematoxylin and eosin staining of the liver biopsy specimen showing a proliferation of tumor cells with hyperchromatic nuclei arranged in trabecular and glandular patterns. b The tumor cells were positive for synaptophysin. $\mathbf{c}$ The Ki-67 index was $29.1 \%$. Original magnification for each $\times 100(a-c)$. 


\section{Case Reports in Oncology}

Hiraide et al.: Long-Term Efficacy of S-1 Chemotherapy plus Administration of

Octreotide for a Patient with Metastatic Neuroendocrine Tumor (Gastrinoma)

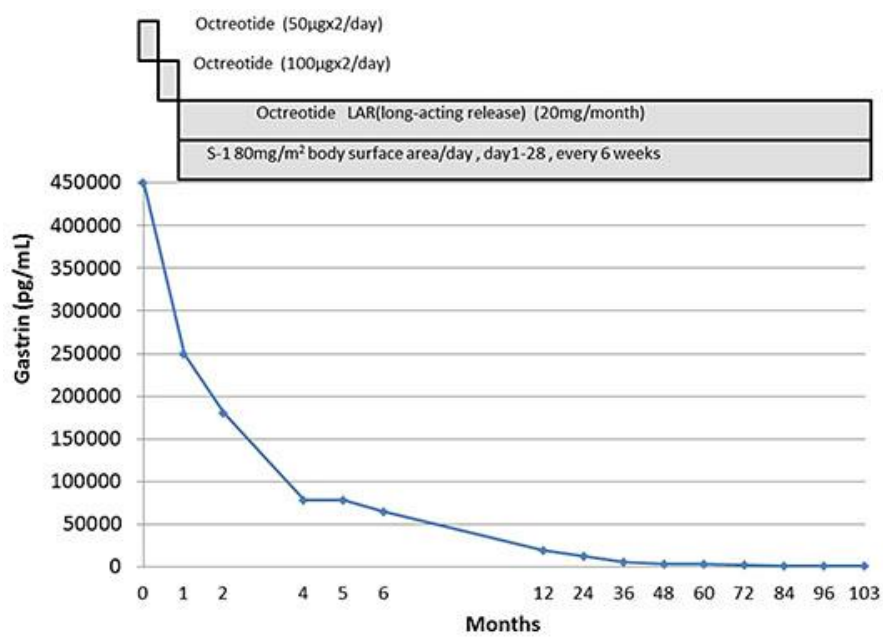

Fig. 3. The clinical course of this case. The gray boxes indicate the clinical treatment. In the lower graph, the blue line indicates serum gastrin level. Serum gastrin level decreased after administration of octreotide and S-1. 
Hiraide et al.: Long-Term Efficacy of S-1 Chemotherapy plus Administration of

Octreotide for a Patient with Metastatic Neuroendocrine Tumor (Gastrinoma)

Table 1. Clinical data of the 12 pancreatic neuroendocrine neoplasms treated with S-1 (including the present case) reported in the English or Japanese literature

\begin{tabular}{|c|c|c|c|c|c|c|c|c|c|c|}
\hline \multirow[t]{2}{*}{ No. } & \multirow{2}{*}{$\begin{array}{l}\text { Author, } \\
\text { year }\end{array}$} & \multirow{2}{*}{$\begin{array}{l}\text { Age, } \\
\text { sex }\end{array}$} & \multicolumn{2}{|c|}{ WHO grading } & \multirow[t]{2}{*}{ Hormonal state } & \multirow{2}{*}{$\begin{array}{l}\text { Metastatic } \\
\operatorname{site}(\mathrm{s})\end{array}$} & \multirow{2}{*}{$\begin{array}{l}\text { Chemotherapy } \\
\text { including S-1 }\end{array}$} & \multirow[t]{2}{*}{ Outcome } & \multirow[t]{2}{*}{ SSA } & \multirow{2}{*}{$\begin{array}{l}\text { Treatment } \\
\text { used prior to } \\
\text { S-1 }\end{array}$} \\
\hline & & & 2000 & 2010 & & & & & & \\
\hline 1 & $\begin{array}{l}\text { Takeuchi } \\
\text { et al., } 2008\end{array}$ & $79, \mathrm{M}$ & G3 & & Nonfunctioning & $\begin{array}{l}\text { Liver, } \\
\text { lymph } \\
\text { node, lung }\end{array}$ & $\mathrm{S}-1+\mathrm{STZ}$ & PR & No & Surgery \\
\hline 2 & $\begin{array}{l}\text { Masuda } \\
\text { et al., } 2008\end{array}$ & $55, \mathrm{M}$ & NA & & Nonfunctioning & $\begin{array}{l}\text { Liver, } \\
\text { bone }\end{array}$ & $\begin{array}{l}\text { S-1 monotherapy, } \\
\text { S-1 + GEM }\end{array}$ & $\mathrm{SD}, \mathrm{SD}$ & No & $\begin{array}{l}\text { Surgery, } \\
\text { chemotherapy }\end{array}$ \\
\hline 3 & $\begin{array}{l}\text { Nishii et al., } \\
2008\end{array}$ & $60 \mathrm{~s}, \mathrm{~F}$ & MANEC & & Nonfunctioning & Liver & S-1 monotherapy & PD & No & Surgery, TAE \\
\hline 4 & $\begin{array}{l}\text { Nishimura } \\
\text { et al., } 2009\end{array}$ & $50 \mathrm{~s}, \mathrm{~F}$ & NA & & Gastrinoma & Liver & S-1 monotherapy & PD & Octreotide & Surgery, TAE \\
\hline 5 & $\begin{array}{l}\text { Sato et al., } \\
2010\end{array}$ & $73, \mathrm{M}$ & G2 & & Nonfunctioning & Liver & S-1 monotherapy & PR & No & No \\
\hline 6 & $\begin{array}{l}\text { Yamamoto } \\
\text { et al., } 2012\end{array}$ & $42, \mathrm{M}$ & G3 & & Nonfunctioning & Liver & S-1 + GEM & PR & No & No \\
\hline 7 & $\begin{array}{l}\text { Yoshida } \\
\text { et al., } 2013\end{array}$ & $41, F$ & & G3 & Nonfunctioning & Liver & S-1 + GEM & SD & Octreotide & No \\
\hline 8 & $\begin{array}{l}\text { Kanemasa } \\
\text { et al., } 2013\end{array}$ & $63, \mathrm{M}$ & & MANEC & Nonfunctioning & Liver & S-1 monotherapy & PR & No & No \\
\hline 9 & $\begin{array}{l}\text { Yoshizawa } \\
\text { et al., } 2014\end{array}$ & $60 \mathrm{~s}, \mathrm{~F}$ & & G2 & Nonfunctioning & $\begin{array}{l}\text { No } \\
\text { (locally } \\
\text { advanced) }\end{array}$ & S-1 monotherapy & SD & No & No \\
\hline 10 & $\begin{array}{l}\text { Yoshioka } \\
\text { et al., } 2015\end{array}$ & $69, \mathrm{~F}$ & & G1 & Proinsulinoma & $\begin{array}{l}\text { Liver, } \\
\text { lung }\end{array}$ & S-1 + GEM & PD & No & $\begin{array}{l}\text { Surgery, TACE, } \\
\text { chemotherapy }\end{array}$ \\
\hline 11 & $\begin{array}{l}\text { Ikezoe et al., } \\
2015\end{array}$ & $65, \mathrm{M}$ & & G3 & Somatostatinoma & $\begin{array}{l}\text { Liver, } \\
\text { lymph } \\
\text { node }\end{array}$ & $\mathrm{S}-1+\mathrm{CDDP}$ & NA & Octreotide & $\begin{array}{l}\text { Surgery, } \\
\text { chemotherapy }\end{array}$ \\
\hline 12 & Present case & $53, \mathrm{~F}$ & G2 & & Gastrinoma & Liver & S-I monotherapy & PR & Octreotide & No \\
\hline
\end{tabular}

M, male; F, female; NA, not available; MANEC, mixed-adenoendocrine carcinoma; STZ, streptozocin; GEM, gemcitabine; CDDP, cisplatin; PR, partial response; PD, progressive disease; SD, stable disease; SSA, somatostatin analogues; TAE, transarterial embolization; TACE, transarterial chemoembolization. 